\title{
ANALISIS PRODUK TABUNGAN IB MUAMALAT PRIMA BISNIS TERHADAP SEKTOR RILL PEREKONOMIAN MASYARAKAT (STUDI KASUS PT. BANK MUAMALAT INDONESIA, TBK CABANG BANJARMASIN
}

\author{
Agus Purnomo \\ Program Studi Ekonomi Syariah \\ Fakultas Studi Islam Universitas Islam Kalimantan Muhammad Arsyad Al Banjari \\ Email: agustikazahra80@gmail.com \\ Muhammad Rusdiansyah \\ Program Studi Ekonomi Syariah \\ Fakultas Studi Islam Universitas Islam Kalimantan Muhammad Arsyad Al Banjari \\ Email: muhmrusdiansyah@yahoo.com
}

\section{ARTICLE HISTORY}

Received:

4 December 2018

Accepted:

28 June 2019

Online available:

30 June 2019

\section{Keywords:}

Savings Products,

Rill Sector,

Economy Public.

\section{ABSTRACT}

This research is motivated by the researcher who previously conducted the Work Practice in PT.Bank Muamalat Indonesia, Tbk Branch Banjarmasin Years 2016 as Marketing Funding. After knowing the superior Funding Product of Bank Muamalat Indonesia Branch of Banjarmasin ie iB Muamalat Prima Business Savings. The reasercher tries to find out the influence of this Product in addition to beneficial to the Customer but the perceived impact in driving the Customer Business That's where it is. The purpose of this research was undertaken by Benefits of Savings Products iB Muamalat Prima Business as a whole and to determine the effect of Savings Products iB Muamalat Prima Business Against the Rill Sector Field SMEs (Micro Small and Medium Enterprises) community.This research used Qualitative method descriptive qualitative approach. The data obtained then in the form of data information such as observation, interviews, field notes and documentation. For Respondent data source counted to 3 people namely Business Development Manager Funding, Marketing Funding and Customer Service. While informants counted to 5 people namely the Customer Savings Product iB Muamalat Prima Bussiness as entrepreneurs and not entrepreneurs. The results of this research indicate that there is a great influence in mobilizing the Rill Sector of the Economic Community, depending on the Customer itself willing to be used as a transactional tool with business partners or as a Product User Customer. 
Kata Kunci:

Produk Tabungan, Sektor

Perekonomian

Masyarakat.
Penelitian ini dilatarbelakangi oleh penulis yang sebelumnya melakukan Praktik Kerja Lapangan di PT. Bank Muamalat Indonesia, Tbk Cabang Banjarmasin Tahun 2016 sebagai Marketing Funding. Setelah mengetahui Produk Funding unggulanBank Muamalat Indonesia Cabang Banjarmasin yaitu Tabungan iB Muamalat Prima Bisnis. Penulis berusaha mencari tahu pengaruh Produk ini selain menguntungkan bagi Nasabah tapi dampak yang dirasakan dalam menggerakkan Usaha Nasabah itu sampai dimana. Tujuan penelitian ini dilakukan untuk mengetahui Fitur dan Benefit Produk Tabungan iB Muamalat Prima Bisnis secara keseluruhan dan untuk mengetahui pengaruh Produk Tabungan iB Muamalat Prima Bisnis Terhadap Sektor Rill Bidang UMKM (Usaha Mikro Kecil dan Menengah) masyarakat.Penelitian ini menggunakan Metode Kualitatif dengan pendekatan Deskriftif Kualitatif. Data yang didapatkan nanti berupa data informasi seperti observasi, wawancara, catatan lapangan dan dokumentasi. Untuk sumber data Responden berjumlah 3 orang yaitu Business Development Manager Funding, Marketing Funding dan Customer Service. Sedangkan, Informanberjumlah 5 orang yaitu Nasabah Produk Tabungan iB Muamalat Prima Bisnis yang latar belakangnya sebagai pengusaha dan bukan pengusaha. Hasil Penelitian ini menunjukkan ada pengaruh yang besar dalam menggerakkan Sektor Rill Perekonomian Masyarakat, tergantung Nasabah itu sendiri mau dipergunakan sebagai alat transaksional dengan rekan bisnis atau sebagai Nasabah Pengguna Produk.

\section{PENDAHULUAN}

Perbankan memiliki peran yang sangat penting dalam perekonomian suatu negara, dimana tolak ukur keberhasilan suatu negara dilihat dari pengguna sektor kegiatan keuangan. Semakin baik kondisi perbankan suatu negara, makin baik pula kondisi perekonomian suatu negara. Menurut M. Sulhan dan Ely Siswanto (2008) Efektivitas dan efisiensi sistem perbankan di suatu negara akan memperlancar perekonomian pada negara tersebut. Dengan penyaluran dana yang baik, para pelaku ekonomi dapat terbantu dalam pengalokasian dana serta pengaturan dana. Perbankan menjadi pihak yang memiliki spesialisasi dalam manajemen dana nasabah khususnya, kapan harus menggunakan dana untuk modal kerja dan investasi sedangkan nasabah bisnis dapat lebih berkonsentrasi penuh pada proses produksi dan distribusi barang. 
Menurut M.Sulhan dan Ely Siswanto (2008) Artinya perbankan berperan dalam sektor finansial, sedangkan nasabah bisnis berperan sebagai sektor riil. Bank syariah dikenal lebih dekat dengan sektor riil karena produk yang ditawarkan, khususnya dalam pembiayaan, senantiasa menggunakan underlying transaksi di sektor riil sehingga dampaknya lebih nyata dalam mendorong pertumbuhan ekonomi.

Berdasarkan latar belakang masalah maupun strategi pemasaran produk Funding diatas, penulis berusaha mengdeskripsikan fitur dan benefit produk Tabungan iB Muamalat Prima Bisnis dan pengaruh produk Tabungan iB Muamalat Prima Bisnis terhadap Sektor Rill bidang UMKM (Usaha Mikro Kecil dan Menengah) masyarakat yang akan tertuang dalam judul penelitian "ANALISIS PRODUK TABUNGAN IB MUAMALAT PRIMA BISNIS TERHADAP SEKTOR RILL PEREKONOMIAN MASYARAKAT (STUDI KASUS PT. BANK MUAMALAT INDONESIA, TBK CABANG BANJARMASIN )"

\section{LANDASAN TEORI}

Di dalam sejarah perekonomian umat Islam, pembiayaan yang dilakukan dengan akad yang sesuai syariah telah menjadi bagian dari tradisi umat Islam sejak zaman Rasulullah Shallallahu 'alaihi wa sallam. Menurut Burhanuddin Susanto (2008) Bentuk akad seperti menerima titipan, meminjamkan dana dan pembiayaan usaha, serta melakukan berbagai akad terkait dengan jasa keuangan sudah merupakan bagian dari kehidupan muamalah pada saat ini. Perbankan syariah adalah segala sesuatu yang menyangkut tentang Bank Syariah dan Unit Usaha Syariah, mencakup kelembagaan, kegiatan usaha serta cara dan proses dalam melaksanakan kegiatan usahanya (Pasal 1 angka 1 UU No. 21 Tahun 2008 tentang Perbankan Syariah). Menurut Zubaira Hasan (2009) Dalam UU Perbankan Syariah, ketentuan yang diperuntukan untuk Perbankan Syariah disebut dengan "Perbankan Syariah" atau "Bank Syariah dan UUS".

Di Indonesia, Bank Syariah yang pertama didirikan pada tahun 1992 adalah Bank Muamalat Indonesia (BMI). Menurut Adiwarman Karim (2008) Walaupun perkembangannya agak lambat bila dibandingkan dengan negara-negara muslim lainnya cepat ataupun lambat perbankan syariah di Indonesia akan terus berkembang. Ditambah lagi jaringan kantor Bank Muamalat Indonesia tersebar dari seluruh Provinsi di Indonesia, salah satu jaringan kantor Bank Muamalat Indonesia yaitu Bank Muamalat Indonesia Cabang Banjarmasin yang berdiri dan beroperasi pada tanggal 11 September 2003 diresmikan langsung oleh Gubernur Kalimantan Selatan yaitu H.M Sjahriel Darham. Dengan sistem keuangan dan perbankan yang dimiliki, ini merupakan bagian dari konsep yang lebih luas ketika berbicara mengenai Eknonomi Islam. Dimana tujuannya sebagaimana dianjurkan oleh para ulama adalah memberlakukan sistem nilai dan etika Islam ke dalam lingkungan ekonomi. Karena dasar etika inilah, maka keuangan dan 
perbankan Islam bagi kebanyakan Muslim adalah bukan sekedar sistem transaksi komersil.

Persepsi Islam dalam transaksi financial itu di pandang oleh banyak kalangan Muslim sebagai kewajiban agama. Menurut Zainul Ariffin (2003) Kemampuan lembaga keuangan Islam menarik investor dengan sukses bukan hanya tergantung pada tingkat kemampuan lembaga itu menghasilkan keuntungan, tetapi juga pada persepsi bahwa lembaga tersebut secara sungguh-sungguh memperhatikan batas-batas yang digariskan oleh Islam.

Menurut M. Sulhan dan Ely Siswanto (2008) sistem Perbankan yang terdiri dari lembaga, kegiatan usaha, serta cara dan proses pelaksanaan kegiatan usaha yang memungkinkan bank melaksanakan fungsinya dengan baik. Dengan sistem inilah Bank Muamalat Indonesia menyediakan salah satu jasa layanan produk Funding (penanaman dana) untuk mempermudah nasabahnya dalam menghimpun dana dari berbagai kebutuhan nasabahnya. Proses pemasaran produk pendanaan (Funding) Bank Muamalat Indonesia oleh MarketingFunding kian merujuk ke berbagai cara untuk mendapatkan hasil yang maksimal, seperti pendekatan/silaturahmi ke individu atau non individu yang dituju guna mendapatkan tempat strategis dalam mencari nasabah.

Promosi penjualan merupakan bentuk persuasi langsung melalui penggunaan berbagai intensif yang dapat diatur untuk merangsang pembelian produk dengan segera atau meningkatkan jumlah pengguna produk bank (nasabah). Salah satu Produk Tabungan unggulan dari Bank Muamalat Indonesia yaitu "Tabungan iB Muamalat Prima Bisnis". Produk ini diperuntukan kepada nasabah yang ingin menyimpankan dananya disertai dengan fasilitas yang banyak membawa manfaat, sesuai kebutuhan nasabahnya serta mendapatkan keuntungan dari bagi hasil (Nisbah) antara pihak bank dan nasabah. Akses yang luas dengan fasilitas kartu ATM Share-E Gold, ATM Prima layanan Phone Banking, Mobile Banking menjadi fitur layanan dari produk ini dan menjadi lebih menguntungkan dengan adanya program waadnisbah (Komitmen bank berupa tambahan nisbah atas nisbah counter yang berlaku), makin besar saldo tabungan maka akan besar pula tingkat bagi hasilnya. Konsep bauran pemasaran (marketing mix) adalah hal yang sangat menarik dan merupakan sebuah keniscayaan untuk mempercepat pengembangan perbankan syariah di Indonesia. Elemen bauran pemasaran untuk usaha jasa meliputi 7P yaitu product, price, place, promotion, people, process dan physical evidence menurut Gita Danupranata:

1. Product, dalam Bank Muamalat Indonesia bukan berupa barang, melainkan ciri khas jasa yang dihasilkan haruslah mengacu pada syariat 
islam dan diperbolehkan dalam Al-Qur'an. Namun agar dapat menarik nasabah, maka dilakukan strategi dalam produk tersebut.

2. Price, dengan adanya harga tawaran yang sesuai dengan pengorbanan yang dikeluarkan oleh nasabah bisa mendapatkan manfaat dari produk atas pengorbananya seperti adanya akad wadiah, mudharabah, margin, nisbah dan fee. Sehingga harga yang ditawarkan mampu bersaing bahkan berhasil mengungguli perbankan lainnya.

3. Place, Bank Muamalat Indonesia harus bisa bekerjasama oleh instansiinstansi agar lebih cepat dalam menguasai pangsa pasar dan proses yang dilakukan bertahap.

4. Promotion, perlu biaya yang cukup untuk proses pengiklanan, karena iklan dapat mengenalkan secara langsung dan merekam proses promosi ke nasabah agar nasabah bisa lebih tau produk-produk bank.

5. People, dari tingkat kepuasan para nasabah dapat terukur betapa pentingnya pelayanan yang harus dilakukan, agar nasabah memiliki jangka waktu kepuasan yang lebih lama.

6. Process, dengan proses dapat menghasilkan produk berupa jasa yang prosesnya bisa berjalan efektif dan efisien. Selain itu juga bisa diterima dengan baik oleh nasabah.

7. Physical evidence, cara dan bentuk pelayanan kepada nasabah merupakan bukti nyata yang seharusnya bisa dirasakan atau sebagai bukti fisik bagi nasabah.

Dalam produk tabungan prima bisnis yang dimiliki oleh Bank Muamalat disini agar bisa mendorong dan memudahkan para pelaku bisnis yang bergerak dibidang sektor riil. Dalam tabungan IB Muamalat prima bisnis. Pemasaran produk prima bisnis kepada pelaku bisnis yang bergerak di sektor riil sehingga, mempermudah para pelaku sektor riil dalam melakukan transaksi jual dan beli suatu barang dengan menggunakan produk prima bisnis Bank Muamalat Cab Banjarmasin.

\section{METODE PENELITIAN}

Menurut Haris Hardiansyah (2010), Jenis penelitian ini adalah kualitatif dimana bertujuan untuk memahami fenomena dalam konteks sosial secara alamiah dengan mengedepankan proses interaksi komunikasi yang mendalam antara peneliti dengan 
fenomena yang diteliti. Peneliti bisa secara langsung terjun ke lapangan untuk mendapatkan informasi-informasi yang bisa dipertanggung jawabkan keabsahan datanya. Pendekatan dari penelitian ini yaitu deskriftif kualitatif, dimana data yang didapatkan nanti berupa data informasi seperti observasi, wawancara, catatan lapangan dan dokumen pribadi. Dengan jenis dan pendekatan seperti ini, peneliti secara langsung mengetahui dan memahami kasus yang sedang ditelitinya. Penelitian ini mengambil lokasi di PT. Bank Muamalat Indonesia, Tbk Cabang Banjarmasin yang beralamatkan di Jalan Ahmad Yani KM 5,2 No.1 Banjarmasin, Kalimantan Selatan.

Menurut Sugiyono (2014), penentuan sampel atau informan dalam penelitian kuantitatif berfungsi untuk mendapatkan informasi yang maksimum, karena akan dijadikan sampel atau informan sebaiknya yang memenuhi kriteria sebagai berikut :

1. Nasabah Bank Muamalat yang menggunakan produk tabungan IB Prima Bisnis di cab Banjarmasin

2. Nasabah yang mempunyai usaha bergerak di bidang sektor riil di daerah Banjarmasin

3. Karyawan/ staff Bank Muamalat cab Banjarmasin Business Development Manager Funding, Staff Marketing Funding 1 orang, Customer Service 1 orang.

Dalam penelitian ini menentukan informan menggunakan metode purposive sampling, artinya memilih narasumber yang benar mengetahui tentang Produk Tabungan IB Prima Bisnis terhadap transaksi di sektor riil di lihat dari manfaat dan kemudahan nasabah dalam melakukan transaksi jual beli di dalam sektor riil. Pengumpulan data dapat menggunakan data primer dan data sekunder menurut Sugiyono (2014). Sample adalah sebagian dari jumlah dan karakteristik yang dimiliki oleh populasi tersebut. Dalam penelitian ini pengumpulan data menggunakan metode purposive sampling.Menurut Ahad Tanzeh (2009) Data primer meliputi perkataan dan tindakan sedangkan data sekunder meliputi buku-buku, bahan tertulis, artikel, dokumen dan foto. Data dalam penelitian ini berupa data primer dan data sekunder adalah sebagai berikut :

1. Observasi yaitu teknik pencatatan secara sistematis mengenai tingkah laku dengan melihat atau mengamati Responden dan Informan yang diteliti secara langsung.

2. Wawancara yaitu cara pengumpulan data dengan mengajukan pertanyaan kepada Responden dan Informan secara langsung. Dalam 
wawancara pertama kali kepada Business Development Manager Funding, Staff Marketing Funding 1 orang, Customer Service 1 orang mengenai produk tabungan IB Muamalat Prima Bisnis, wawancara yang kedua kepada nasabah pengguna produk Tabungan Prima Bisnis terhadap sektor Riil, sebagai para pelaku bisnis disini nasabah akan menjelaskan apa pengaruh produk tabungan IB Prima Bisnis ini pada para pelaku sektor riil.

3. Dokumentasi yaitu teknik pengumpulan data yang dimaksudkan untuk melengkapi data-data informasi dari hasil wawancara. Seperti gambar/foto, catatan-catatan yang berkaitan dengan penelitian dan lain sebagaianya.

Analisis hasil dan pembahasan adalah cara peneliti mengolah data secara sistematis dari hasil wawancara. Adapun cara yang digunakan yaitu:

1. Editing adalah tahapan awal proses dimana peneliti melakukan pemeriksaan dan pengeditan data yang sudah dikumpulkan.

2. Kategorisasi adalah tahapan kedua proses dimana peneliti melakukan klasifikasi dan memasukan data ke dalam klasifikasi yang sudah ditentukan.

3. Intrepretasi adalah tahapan ketiga proses dimana peneliti melakukan pemahaman dan penafsiran data yang diperoleh.

4. Deskripsi adalah tahapan akhir proses dimana peneliti melakukan penguraian data, menyusun data dan diolah dengan cara yang sistematis.

\section{HASIL DAN PEMBAHASAN}

\section{Produk Tabungan iB Muamalat Prima}

Tabungan iB Muamalat Prima Bisnis adalah salah satu Produk unggulan Funding Bank Muamalat Indonesia, produk ini memiliki 3 jenis yaitu :

1) Tabungan iB Muamalat Prima Berhadiah

2) Tabungan iB Muamalat Prima

3) Tabungan iB Muamalat Prima Bisnis 
Pada prinsipnya jenis Tabungan ini tidak jauh berbeda dengan produk tabungan perbankan syariah lainnya dengan adanya Nisbah (bagi hasil). Hanya saja, produk ini cukup di unggulkan karena keuntungan Nisbah (bagi hasil) hampir setara dengan Produk Deposito Bank Muamalat Indonesia, misal Nasabah 50 \% dan Bank 50 \% (tergantung ketentuan Bank). Nisbah (bagi hasil) yang dimaksudkan hampir setara dengan Produk Deposito Bank Muamalat Indonesia adalahNisbah ( 5\%) + Waad Nisbah (25 \% atau 35 \%).

Waad nisbah adalah komitmen Bank berupa tambahan nisbah atas nisbah counter yang berlaku). Jadi, Nisbah (bagi hasil) yang didapatkan oleh Nasabah bisa sebesar $30 \%$ atau 40 \% sedangkan Bank $70 \%$ atau 60 \% Adapun, pengguna dari produk ini kebanyakan berasal dari kalangan ekonomi menengah keatas.

Dari hasil wawancara kepada R. Jarot Teja Purnomo selaku BDM Funding jumlah data Nasabah Produk Tabungan iB Muamalat Prima Bisnis di tahun 2016 "Pertumbuhan Produk ini sangat baik per semester ( 6 bulan) tumbuh 20-30\% dan di totalkan selama 1 tahunnya 36 \%. Untuk latar belakang pekerjaan Nasabah Produk Tabungan iB Muamalat Prima Bisnis berasal dari berbagai macam lapisan masyarakat baik itu PNS, Karyawan, Karyawati, Ibu Rumah Tangga, Pengusaha, Perusahaan dan lain sebagainya. Padahal Produk ini memang dikhususkan atau lebih ideal kepada Nasabah Bisnis tapi Nasabah Non Bisnis juga begitu antusias melihat fasilitas yang diberikan" Sehingga dapat disimpulkan pertumbuhan Produk Tabungan iB Muamalat Prima Bisnis diperkirakan akan semakin berkembang tiap tahunnya. Yang menjadi alasan kenapa produk ini bisa berkembang tiap tahunnya di karenakan kebanyakan para nasabah menggunakan produk ini sebagai sarana untuk melestarikan budaya menabung yang aman maupun berkah di Perbankan Syariah, mendapatkan bagi hasil yang besar dan sebagai alat transaksional nasabah dengan para rekan bisnisnya.

Menurut hasil wawancara kepada RM Funding mengenai manfaat Produk Tabungan iB Muamalat Prima Bisnis bagi nasabah adalah dengan adanya produk ini nasabah bisa merasakan berbagai macam kebutuhan dan keinginan tergantung tujuan nasabah. Bank Muamalat Indonesia mengeluarkan produk ini tentunya tidak harus digunakan sebagai sarana menabung saja, melainkan mencari nasabah bisnis. Produk ini dikhususkan kepada nasabah yang menyimpankan dananya dengan jumlah besar itu diberikan sebuah fasilitas menguntungkan bagi nasabah-nasabahnya seperti waad nisbah, Free pilihan nomor rekening cantik sesuai permintaan nasabah sepanjang nomor rekening cantik belum digunakan oleh nasabah sebelumnya, Gratis biaya transfer in/out meliputi transfer melalui Fund Transfer (FT), Gratis biaya Airport Lounge, e-channel, SKN (Sistem Kliring Nasional) dan RTGS (Real Time Gross Settlement). 
Fasilitas yang sudah disebutkan diatas selain waad nisbah, semua dapat dirasakan keseluruhan tergantung dengan jumlah dana yang sudah ditentukan oleh pihak Bank Muamalat Indonesia. Dengan memiliki identitas Nasabah Prima Bisnis, nasabah akan diberikan perlakuan khusus demi kemudahan dan kenyamanan transaksi nasabah baik menabung maupun transaksi keuangan kepada rekan bisnis.

Benefit Produk Tabungan iB Muamalat Prima Bisnis

a) Akses yang luas, difasilitasi Kartu Share-E Gold dan Layanan Phone Banking, Internet Banking serta Mobile Banking.

b) Lebih menguntungkan dengan adanya program waad nisbah. Lebih besar saldo tabungan, lebih tinggi bagi hasilnya hampir setara dengan Produk Deposito.

Menurut Hasil Wawancara ibu Windy pengusaha batubara dari manfaat produk Tabungan IB Muamalat Prima Bisnis adalah Produk Tabungan iB Muamalat Prima Bisnis keuntungan bagi hasil yang didapat setara dengan bagihasil deposito, fasilitas produk tabungan IB Prima Bisnis Gratis biaya transfer in/out meliputi transfer melalui Fund Transfer (FT), Gratis biaya Airport Lounge, e-channel, SKN (Sistem Kliring Nasional) dan RTGS (Real Time Gross Settlement).

\section{PRODUK TABUNGAN IB MUAMALAT PRIMA BISNIS TERHADAP SEKTOR RILL PEREKONOMIAN MASYARAKAT.}

Pengaruh yang dapat dirasakan Produk Tabungan iB Muamalat Prima Bisnis dalam menggerakkan Sektor Rill bidang Usaha Mikro Kecil dan Menengah (UMKM) adalah tidak berdampak signifikan kepada sasaran nasabah bisnisnya karena produk ini masih tergolong baru jalan 2 tahun dan masih banyak nasabah-nasabah yang belum tahu fasilitas yang diberikan. Menurut wawancara ibu Nurul Qomariah selaku RM Funding Bank Muammalat adalah Tabungan iB Muamalat Prima Bisnis memang dikhususkan untuk nasabah bisnis supaya transaksional menguntungkan dan pelayanannya pun dikhususkan. Kebanyakan nasabah hanya menabung dan keuntungan bagi hasilnya bisa ditabung kembali untuk keperluan modal usaha maupun kebutuhan lainnya. Dalam produk tabungan IB Muammalat Prima Bisnis free biaya administsi perbulan apabila saldo nasabah mencapai Rp 50.000.00, sehingga nasabah dalam melakukan transaksi dengan rekan bisnis dengan menggunakan fasilitas Bank Muammalat seperti : transfer melalui Fund Transfer (FT), e-channel, SKN (Sistem Kliring Nasional) dan RTGS (Real Time Gross Settlement) dan juga gratis biaya Airport Lounge tanpa dikenakan biaya administrasi. Dengan fasilitas ini Nasabah Bisnis akan merasa lebih mudah dalam mentransfer uangnya kepada rekan bisnisnya secara cepat dan aman. Tetapi, semua 
fasilitas ini bisa didapatkan seluruhnya tergantung ketentuan saldo yang sudah ditentukan pihak bank.

Untuk pengaruh nisbah (bagi hasil) yang dirasakan oleh nasabah setelah menyimpankan dananya dengan jumlah besar. Maka, nasabah akan mendapatkan keuntungan bagi hasil bukan hanya bersifat nisbah (bagi hasil) $5 \%$ Nasabah dan $95 \%$ Bank. Melainkan adanya waad nisbah (komitmen bank berupa tambahan nisbah atas nisbah counter yang berlaku) misal dari $5 \%+25 \%$ menjadi $30 \%$ Nasabah dan $70 \%$ Bank. Contohnya, nisbah (bagi hasil) yang didapat selama 1 (satu) bulannya apabila saldo Nasabah berkisar Rp. 100.000.000,- dengan perhitungan nisbah (bagi hasil) sesuai ketentuan berjumlah Rp. 225.600,-sedangkan untuk total nisbah (bagi hasil) yang didapat selama setahun berjumlah Rp. 2.707.200,-. Dari beberapa fasilitas yang disebutkan diatas dapat disimpulkan apabila nasabah bisnis menggunakan produk ini sangat berpengaruh dalam menggerakkan Sektor Rill bidang Usaha Mikro Kecil dan Menengah (UMKM), karena dapat mempermudah dalam proses transaksi dengan rekan bisnisnya secara cepat, aman dan menguntungkan sehingga menunjang keberlangsungan usahanya sukses.

Menurut wawancara Ibu Syarifah bukan pengusaha tetapi profesi beliau sebagai Tabib ditempat beliau berada. Untuk pengaruh yang dirasakan oleh Produk Tabungan iB Muamalat Prima Bisnis terhadap usaha yang akan Ibu Syarifah rencanakan adalah setelah dipikir-pikir Ibu Syarifah melihat pengaruh fasilitas dari Produk Tabungan iB Muamalat Prima Bisnis ini ideal dalam menjalankan sebuah usaha. Sangat disayangkan apabila fasilitas ini tidak dipergunakan sebagai alat transaksional. Semua fasilitas menunjang kenyamanan transaksional dengan rekan bisnis. Misal, rekan bisnis perlu transfer uang cepat dengan jumlah yang besar, fasilitas produk ini free TransferRTGS (Real Time Gross Settlement) atau menggunakan SKN (Sistem Kliring Nasional). Fasilitas lain seperli free e-channel dan Airport Lounge juga membantu kenyamanan dalam menjalankan sebuah usaha maupun keperluan lainnya.

Untuk pengaruh nisbah (bagi hasil) yang dirasakan dalam menggerakkan usaha sangatlah besar, keuntungan nisbah (bagi hasil) hampir setara dengan Produk Deposito, setelah dipertimbangkan cukup lama ternyata Ibu Syarifah berusaha mengumpulkan modal usaha sedikit demi sedikit. Dengan keuntungan yang didapat dari dua produk funding ini dan tentunya juga harus melihat terlebih dahulu dana penyimpanan yang sudah ditransaksikan dan melihat keuntungan dari Deposito tiap jangka waktu bulannya maupun tahunnya apabila sudah dirasa cukup untuk modal usahanya. Maka, dana akan disimpan kembali ke Tabungan iB Muamalat Prima Bisnis dan dijadikan alat transaksional untuk kemudahan dalam berbisnis nantinya. Untuk usaha yang sudah direncanakan oleh 
Ibu Syarifah yaitu usaha jasa perjalanan umrah dan haji yang akan dikelola langsung oleh beliau dan keluarganya.

Menurut hasil wawancara dengan Ibu Windy selaku pengusaha batubara adalah pengaruh fasilitas yang dirasakan setelah Ibu Windy menggunakan Produk Tabungan iB Muamalat Prima Bisnis dalam menjalankan usaha ialah fasilitas yang didapat seperti proses transaksi antar pembeli jadi lebih nyaman dan cepat. Dengan menggunakan $e-$ channel Mobile Banking Ibu Windy tinggal cek aktivitas saldo tabungan dan mentransfer uang gajihan karyawan beliau maupun transfer uang pembelian batu bara dengan jumlah sedikit kepada rekan bisnis. Hanya saja biaya yang dikenakan dari fasilitas ini adalah transfer uang ke Bank lain Rp. 6.500 dan biaya kuota internet. Selain dari itu gratis seperti biaya administasi bulanan e-channel Mobile Banking dantransfer uang ke sesama Bank Muamalat Indonesia. Fasilitas transfer uang dengan jumlah besar sepeti SKN (Sistem Kliring Nasional) dan RTGS (Real Time Gross Settlement) juga sangat membantu Ibu Windy dalam melakukan transaksional dengan rekan bisnisnya dalam jangka waktu yang cepat dan aman. Untuk pengaruh nisbah (bagi hasil) setelah menggunakan produk ini adalah sangatlah menguntungkan. Keuntungan yang didapat selain fasilitas yang ideal dengan pembinis, tapi keuntangan nisbah (bagi hasil) selama 1 bulan sampai 1 tahunnya, bisa dijadikan tambahan modal usaha dan dijadikan sumber pengembangan Usaha Mikro Kecil dan Menengah (UMKM) baru yang akan dijalankan oleh adik Ibu Windy ataupun sebagai keperluan lainnya.

Menurut Hasil Wawancara dengan Ibu $\mathrm{Hj}$. Siti selaku pengusaha Distributor Pakaian Bayi adalah pengaruh yang dirasakan setelah Ibu $\mathrm{Hj}$. Siti menggunakan Produk Tabungan iB Muamalat Prima Bisnis ialah pengaruh fasilitas yang diberikan membantu dalam proses bisnis Usaha Mikro Kecil dan Menengah (UMKM) yang Ibu Hj. Siti jalankan, biasanya Ibu $\mathrm{Hj}$. Siti menggunakan fasilitas free Airport Lounge ketika bepergian keluar kota membeli barang untuk diperjualbelikan, aktivitas transaksi dengan rekan bisnis Usaha Mikro Kecil dan Menengah (UMKM) terasa lebih mudah dengan adanya fasilitas $e$ channel Mobile Banking Ibu Hj. Siti tinggal melakukan transaksi melalui ini, tidak perlu susah-susah mencari ATM (Authomatic Teller Machine) Bank Muamalat Indonesia terlebih dahulu, fasilitas lain seperti SKN (Sistem Kliring Nasional) sangat membantu Ibu $\mathrm{Hj}$. Siti melakukan transfer uang ke rekan bisnis dengan jumlah uang yang sangat besar dan prosesnya pun cepat. Untuk pengaruh nisbah (bagi hasil) yang didapat sangat besar, hampir setara dengan Produk Deposito, Produk Tabungan iB Muamalat Prima Bisnis lebih bisa digunakan setiap saat dan menguntungkan dibanding Produk Deposito yang hanya sebagai produk investasi. Keuntungan nisbah (bagi hasil) yang didapat lbu $\mathrm{Hj}$. Siti selama setahun bisa digunakan untuk menambah modal usaha ataupun membantu dalam hal keperluan lainnya. 
Menurut hasil wawancara dengan Ibu Muliana selaku Agent SPBU dan LPG adalah pengaruh yang dirasakan setelah Ibu Muliana menggunakan Produk Tabungan iB Muamalat Prima Bisnis ialah pengaruh fasilitas yang didapat sangat memfasilitasi proses jual beli dengan rekan bisnis Usaha Mikro Kecil dan Menengah (UMKM) yang sudah dijalin selama bertahun-tahun. Seperti adanya fasilitas e-channel Mobile Banking Ibu Muliana tidak perlu pusing harus mencari (Authomatic Teller Machine) Bank Muamalat Indonesia kemudian melakukan transaksi dengan pembelinya. Selain itu fasilitas free Airport Lounge memudahkan Ibu Muliana ketika bepergian ke luar kota baik hal berbisnis ataupun keperluan lainnya. Dari tiap transaksi dengan rekan bisnis biasanya Ibu Muliana menggunakan fasilitas SKN (Sistem Kliring Nasional) dan RTGS (Real Time Gross Settlement) supaya keamanan uang terjamin aman dan kepuasan pembeli ataupun penjual dapat dirasakan dengan adanya produk ini, Ibu Muliana tidak perlu susah-susah bawa uang banyak diatas/dibawah Rp. 100 juta sampai Rp. 1 Milyar keatas/kebawah. Untuk pengaruh nisbah (bagi hasil) Ibu Muliana merasa sangat diuntungkan dengan adanya fasilitas waad nisbah walaupun Produk Tabungan tapi keuntungannya hampir setara dengan Produk Deposito. Jadi, keuntungannya bisa dipergunakan untuk kepentingan usaha atau kepentingan pribadi ditambah lagi free biaya administrasi 1 bulannya.Dengan adanya Produk Tabungan iB Muamalat Prima Bisnis Ibu Muliana merasa terbantu dengan semua pengaruh fasilitas dan nisbah (bagi hasil) yang didapat. Karena, selain menunjang keberlangsungan usahanya sukses, tapi bisa mengembangkan usaha yang sudah ada dan menciptakan Usaha Mikro Kecil dan Menengah (UMKM) yang baru selain agent SPBU dan LPG.

Menurut hasil wawancara dengan Ibu $\mathrm{Hj}$. Faridah selaku importir aspal adalah pengaruh yang dirasakan setelah lbu $\mathrm{Hj}$. Faridah menggunakan Produk Tabungan iB Muamalat Prima Bisnis ialah fasilitas yang ditawarkan sangat berpengaruh dalam menunjang perkembangan Usaha Mikro Kecil dan Menengah (UMKM) yang sedang berjalan selama bertahun-tahun, proses jual beli antar rekan bisnis dan memberikan gaji karyawan lebih mudah, cepat dan aman. Pihak Bank memberikan pelayanan maksimal terhadap produk ini Ibu $\mathrm{Hj}$. Faridah yang umurnya sudah tidak muda lagi, mendapatkan pelayanan dimana sewaktu lbu $\mathrm{Hj}$. Faridah menginginkan penarikan tunai atau setoran tunai, pihak Marketing bersedia membantu lbu $\mathrm{Hj}$. Faridah dalam proses transaksi ini. Fasilitas lain seperti SKN (Sistem Kliring Nasional) dan RTGS (Real Time Gross Settlement) juga membantu dalam proses pembelian dan penjualan Aspal kepada rekan bisnisnya. Fasilitas free Airport Lounge juga memudahkan Ibu $\mathrm{Hj}$. Faridah ketika bepergian ke luar kota dengan keluarga dan rekan bisnis. Dengan adanya Produk Tabungan iB Muamalat Prima Bisnis Ibu $\mathrm{Hj}$. Faridah bisa tetap memberikan kenyamanan dengan rekan bisnis yang loyal maupun bisa membuat rekan bisnis baru menjadi pelanggan tetap. Pengaruh 
lain yang dirasakan oleh Ibu Hj. Faridah ialah keuntungan nisbah (bagi hasil) yang didapat bisa dipergunakan sebagai kepentingan pribadi dan kepentingan usahanya.

\section{SIMPULAN}

Berdasarkan hasil penelitian mengenai "Pengaruh Produk Tabungan iB Muamalat Prima Bisnis Terhadap Sektor Rill Perekonomian Masyarakat (Studi Kasus PT. Bank Muamalat Indonesia, Tbk Cabang Banjarmasin)" yang perolehan datanya dilakukana melalui observasi, wawancara, catatan lapangan dan dokumentasi. Penulis menyimpulkan dari hasil penelitian ini sebagai berikut :

1. Fitur dan Benefit dari Produk Tabungan iB Muamalat Prima Bisnis adalah akad yang digunakan Mudharabah Mutlaqah, setoran untuk saldo awal berjumlah Rp. 5.000.000,- , saldo minimum Rp. 50.000,- , Nisbah (bagi hasil) saldo < Rp. 100.000.000,- hanya mendapatkan Nisbah (bagi hasil) sebesar $5 \%$ sedangkan saldo Rp. 100.000.000,- sampai dengan < Rp. 250.000.000,- mendapatkan Nisbah (bagi hasil) sebesar $30 \%$ dan untuk saldo > Rp. 250.000.000,- mendapatkan Nisbah (bagi hasil) sebesar $40 \%$, gratis biaya transfer (in/out), meliputi transfer melalui Fund Transfer (FT), e-channel, SKN (Sistem Kliring Nasional) dan RTGS (Real Time Gross Settlement) semua fasilitas ini bisa dirasakan apabila saldo Nasabah > Rp. 100.000.000,- dengan catatan ada batasan ketentuan pengguna bisa menggunakan hanya beberapa kali hingga Unlimited per bulannya tergantung batasan saldo-saldo yang telah ditentukan oleh Bank dan gratis biaya Airport Lounge apabilasaldo Nasabah > Rp. 100.000.000,- dengan catatan ada batasan ketentuan pengguna bisa menggunakan hanya beberapa kali hingga Unlimited per bulannya tergantung batasan saldo yang telah ditentukan oleh Bank. Adapun Benefit dari Produk Tabungan iB Muamalat Prima Bisnis adalah akses yang luas, difasilitasi kartu ATM (Authomatic Teller Machine) Share-E Gold dan layanan Phone Banking, Internet Banking serta Mobile Banking dan lebih menguntungkan dengan adanya program waad nisbah, lebih besar saldo tabungan maka lebih besar bagi hasilnya hampir setara dengan Nisbah (bagi hasil) Produk Deposito.

2. Pengaruh Produk Tabungan iB Muamalat Prima Bisnis dalam menggerakkan Sektor Rill Bidang Usaha Mikro Kecil dan Menengah (UMKM) masyarakat adalah dapat dilihat dari pengaruh fasilitas produk yang diberikan kepada Nasabah. Pengaruhnya ialah apabila pengguna Produk Tabungan iB Muamalat Prima Bisnis ialah Nasabah Bisnis. Maka, Nasabah merasa akan terbantu dengan fasilitas-fasilitas yang diberikan dapat memudahkan Nasabah dari tiap proses transaksinya. Kenyamanan antar pembeli tetap berjalan lancar dan dengan adanya produk ini Pengaruh keuntungan 
Purnomo \& Rusdiansyah | Jurnal Ekonomi dan Bisnis Islam, Vol. 5, No. 1, Januari-Juni

Nisbah (bagi hasil) yang didapat hampir setara Produk Deposito bisa menambah modal usaha maupun digunakan untuk berbagai kebutuhan Usaha Mikro Kecil dan Menengah (UMKM) yang sedang berjalan atau Usaha Mikro Kecil dan Menengah (UMKM) yang sedang direncanakan sedangkan untuk Nasabah Non Bisnis pengaruh yang dirasakan ialah dengan adanya produk ini, Nasabah merasa sangat menguntukan dari fasilitas yang didapat dan keuntungan nisbah (bagi hasil) yang hampir setara dengan Produk Deposito bisa mengubah pemikiran tidak hanya menyimpan dana tapi merencanakan sebuah Usaha Mikro Kecil dan Menengah (UMKM) yang dijalankan pada waktu mendatang.

\section{DAFTAR PUSTAKA}

Alfani H. Muhammad. (2009). Teori Ekonomi Mikro. Fakultas Ekonomi Universitas Islam Kalimantan Muhammad Arsyad Al-Banjari

Ascarya. (2008). Akad \& Produk Bank Syariah. Jakarta : PT Raja Grafindo Persada

Ascarya. (2011). Akad dan Produk Bank Syariah. Jakarta : Rajawali Pers

Departemen Agama Republik Indonesia. (2016). Al-Qur'an dan Terjamah. Solo : PT. Tiga Serangkai Pustaka Mandiri

GITA DANUPRANATA, G. I. T. A. (2013). Buku Ajar Manajemen Perbankan Syariah.

Hasan, Z. (2009). Undang-Undang Perbankan Syariah: Titik Temu Hukum Islam dan Hukum Nasional. Rajawali Pers.

Haris, H. (2010). Metodologi Penelitian Kualitatif untuk IImu-IImu Sosial. Jakarta: Salemba Humanika.

Kasmir. (2010). Dasar-Dasar Perbankan. Jakarta : Rajawali Pers

Karim, A. Adiwarman. (2008). Bank Islam: Analisis Fiqih dan Keungan. Jakarta: Pt. Raja Grafindo Persada.

Leonardus, S. (2014). Kewirausahaan: Teori, Praktik, dan Kasus-kasus. Jakarta: Penerbit Salemba Empat. 
Ma'ruf, A. H. (2006). Hukum Perbankan dan Perkembangan Bank Syariah Di Indonesia.

Primiana, I. (2009). Menggerakkan Sektor Riil UKM \& Industri. Bandung: Alfabeta.

Sugiyono. (2014). Metode Penelitian Bisnis (Pendekatan Kuantitatif, Kualitatif dan R\&D). Bandung : CV. Alfabeta.

Sujarweni, V. W. (2014). Metodologi Penelitian: Lengkap, praktis, dan mudah dipahami. Yogyakarta: Pustakabarupress.

Sukirno Sadono. (2014). Mikroekonomi Teori Pengantar. Jakarta : Rajawali Pers

Sulhan, M., \& Siswanto, E. (2008). Manajemen Bank Konvensional dan Syariah. Malang: UIN-Malang Press.

Supriyono, M. (2011). Buku Pintar Perbankan. Penerbit Andi.

Susanto Burhanuddin. (2008). Hukum Perbankan Syariah Di Indonesia. Yogyakarta : UII Press

Sutan, R. S. (2014). Perbankan Syariah, Produk-produk dan Aspek-Aspek Hukumnya. Jakarta: Kencana Prenadamedia Group.

Rahmadi, P. M. P. (2011). Banjarmasin.

Tanzeh, A. (2009). Pengantar metode penelitian.

Tjiptono, F. (2008). Strategi Pemasaran . Yogyakarta: CV. Andi Offset.

Triandaru, S., \& Budisantoso, T. (2006). Bank dan Lembaga Keuangan Lain. Jakarta: Salemba Empat.

Warkum, S. (1996). Asas-Asas Perbankan Islam dan Lembaga-Lembaga Terkait (BMUI \& Takaful) di Indonesia. Jakarta: PT. Raja Grafindo Persada.

Winardi, J. (2005). Manajemen Perubahan (The Management Of Change). Jakarta : Kencana 
Purnomo \& Rusdiansyah | Jurnal Ekonomi dan Bisnis Islam, Vol. 5, No. 1, Januari-Juni

Wiratna, V. S. (2014). Metodologi penelitian. Yogyakatra: PT. Pustaka Baru.

Zainul, A. (2002). Dasar-Dasar Manajemen Bank Syariah. Jakarta: Alfabeta. 